\title{
Data-Link and Surface Map Traffic Intent Displays for NextGen 4DT and Equivalent Visual Surface Operations
}

\author{
Kevin J. Shelton*, Lawrence (Lance) J. Prinzel III, Jarvis (Trey) J. Arthur III, \\ Denise R. Jones, Angela S. Allamandola, and Randall E. Bailey \\ NASA Langley Research Center, Hampton, VA, USA 23681
}

By 2025, U.S. air traffic is predicted to increase 3-fold and may strain the current air traffic management system, which may not be able to accommodate this growth. In response to this challenge, a consortium of industry, academia and government agencies have proposed a revolutionary new concept for U.S. aviation operations, termed the Next Generation Air Transportation System or "NextGen". Many key capabilities are being identified to enable NextGen, including the concept of "net-centric" operations whereby each aircraft and air services provider shares information to allow real-time adaptability to ever-changing factors such as weather, traffic, flight trajectories, and security. Data-link is likely to be the primary source of communication in NextGen. Because NextGen represents a radically different approach to air traffic management and requires a dramatic shift in the tasks, roles, and responsibilities for the flight deck, there are numerous research issues and challenges that must be overcome to ensure a safe, sustainable air transportation system. Flight deck display and crew-vehicle interaction concepts are being developed that proactively investigate and overcome potential technology and safety barriers that might otherwise constrain the full realization of NextGen.

Keywords: Data-link, surface maps, situation awareness, aviation safety, equivalent visual operations, runway incursions, taxi conflicts, low-altitude alerting, flight-deck display, Next Generation Air Transportation System

\section{BACKGROUND}

\subsection{Next Generation Transportation System}

NextGen represents a revolutionary approach to air traffic management that requires a shift in the tasks, roles, and responsibilities for all operators, including the flight deck. There are numerous research issues and challenges that must be overcome to ensure a safe, sustainable air transportation system. NextGen envisions the movement of large numbers of people and goods in a safe, efficient, and reliable manner. NextGen will remove many of the constraints in the current air transportation system, support a wider range of operations, and deliver an overall system capacity up to 3 times that of current operating levels. New capabilities are envisioned for NextGen, including four-dimensional trajectory (4DT) operations, equivalent visual operations (EVO), super density arrival/departure operations, and network-centric operations. As part of this work, NASA is focused on issues associated with the NextGen Terminal Maneuvering Area (TMA) to include: 1) the impact of emerging NextGen operational concepts, such as equivalent visual operations (EVO) and four-dimensional trajectory (4DT) operations; 2) the effect of changing communication modalities within a net-centric environment; and 3) the influences from increased pilot responsibility for self-separation and navigation performance compliance.

\subsection{Voice Communications}

Verbal communication is the most efficient and adaptable form of communication and has inherent advantages including speed of transmission, human tone to express urgency and intention, flexibility of dialogue, and provision of party-line or broadcast effect. Pilot-Air Traffic Control (ATC) aural communications have historically been quite successful yet far from error-free. One content analysis showed that $40 \%$ of ATC-pilot communications contained at least one irregularity [1], but the error rate was less than one percent [2]. Fortunately, 60 to $80 \%$ of these errors were caught in

*k.j.shelton@larc.nasa.gov; phone 1757864 4470; fax 1757864 7793; www.nasa.gov 
the read-back process. However, the proportion of corrected read-back errors varied, where the highest workload sectors had the least corrections: en route controllers corrected $89 \%$ of the read-back errors, TRACON and local controllers caught only $60 \%$, and $63 \%$, respectively, and only $50 \%$ of the read-back errors on the ground frequency were corrected.

Problems with language interpretation, clarity, radio congestion (blocked transmissions), confusion, read-back errors, message factors (formulation, packaging, and delivery), and extraneous environmental noise can lead to misunderstandings during voice message reception [3]. Cushing [4] categorized these into groups involving communication problems based on language and those based on non-language. Language-based communication problems include ambiguity, homophony, punctuation, intonation of speech, speech act, problems with reference (including uncertain reference, uncertain addressee, and unclear hand-offs), problems with inference (including implicit and lexical inferences, unfamiliar terminology, and false assumptions), and problems involving repetition (such as no read-back, partial read-backs, ritualization of speech, and cultural issues). Non-language communication problems [4] include issues with numbers (including range overlaps and transposition) problems with radios (including loss of radio and misuse of radios), and problems with compliance (such as distractions, interruptions, fatigue, non-cooperation, etc.).

\subsection{Data-Link Communications}

1.3.1 The Need. The rapidly decreasing availability of radio-frequency bandwidth is driving a rapid shift from voice to data-link. The Eurocontrol/FAA Future Communications Study Operational Concepts and Requirements Team stated, "The growth in aviation traffic has resulted in enormous pressure on the ability of existing spectrum resources to satisfy communications requirements. The very high frequency (VHF) spectrum is already congested and will be the significant limiting factor in Air Traffic Management (ATM) capacity by 2015 unless additional air/ground communication sources are made available to supplement the existing system" [5]. By the year 2015, only $60 \%$ of communications are projected to be provided via voice during the most critical phases of flight in the Airport/Terminal Maneuvering Area (TMA). By 2030, 85\% of Air Traffic Services communications are projected to be provided via data-link in the TMA environments [5].

1.3.2 The Benefits. A key enabler of operations envisioned under NextGen is data-link communications and a voice-byexception (i.e., data-link for routine communications) airspace environment. Data-link communications are a critical determinant to the expansion of air traffic capacity and to the success of an adaptable, "net-centric" operational capability under NextGen. As presently envisioned, the data-link interface changes the modality of pilot-ATC communications from aural to visual using text read-outs on the Flight Management System (FMS) Control-Display Unit (see Figure 1). With this modality shift, research shows data-link communications generally provide the following positive benefits for pilot-ATC communications [6] - 13].

- Reduction or elimination of message blocking and congestion

- Higher efficiency and capacity of communications system resulting in improvement of message delivery time (i.e., when compared to current limited radio-frequency bandwidth, stepped-on messages, and controller-pilot read-back times)

- $\quad$ Persistence of the message

- Unloaded memory burden from lengthy messages, and ability to review later

- Improved information-processing efficiency and accuracy

- Possibility of effective multitasking due to user-pacing communication tasks and elimination of continuous listening workload

- Ability to enable automatic gating that may improve information transfer to other ATC and flight deck subsystems

- Inherently easier and more accurate communications for crews with language and cultural barriers 


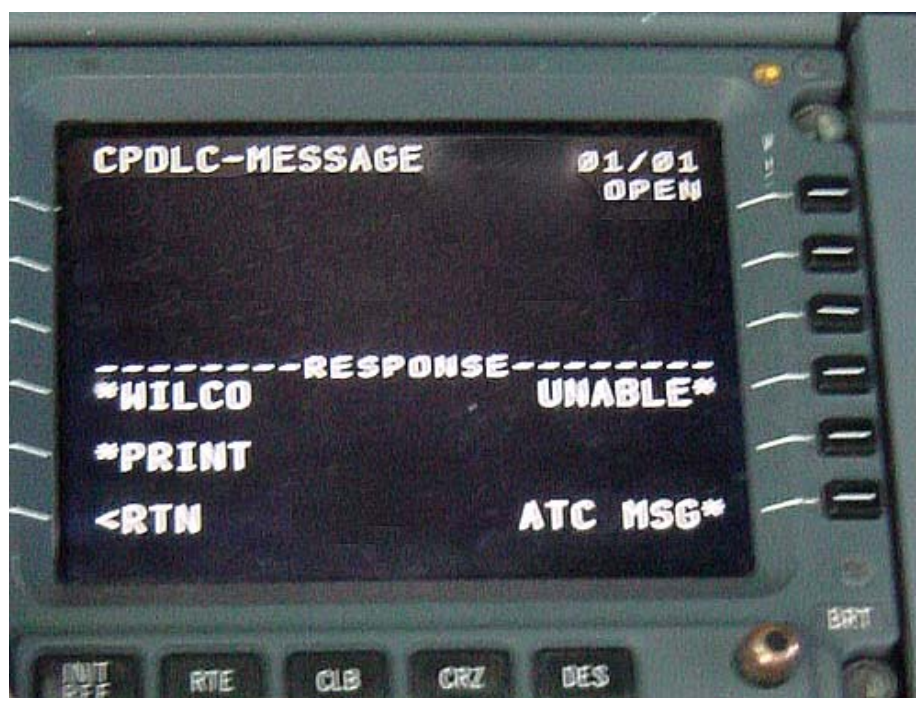

Figure 1: Controller-Pilot Data-Link Capability Demonstration

1.3.3 The Issues. While the transition to data-link communications would appear to be extremely beneficial, there are also many issues/concerns to be addressed. Research has shown that:

- Keyboard FMS implementations might be advantageous to non-English-native languages and cultures, but native users find the interaction to be cumbersome and reading is slower compared to aural/oral communication

- Workload and increased "head-down time" are a major concern [6] [14]

- Users are not able to gain a sense of urgency when using text instead of voice. Data-link does not adequately convey urgency and other natural voice information [15] [8]

- Users may be deprived of "party-line” information [18]

- Crew coordination, diffusion of responsibility, and reduced cross-check involving automation can occur, particularly when data-link is "message-gated" and passed directly into FMS without the pilot reading the message and entering the data manually [15] [9] [16] [17]

- Data-link changes the information processing requirements in the cockpit, requiring more manual interaction and fewer verbal responses than radio, and is more susceptible to interference and decay

1.3.4 Research Need. Navarro and Skiorski [19] detailed the advantages and disadvantages of data-link for today's commercial operations. Although 10 years old, the review documented the prevailing issues that continue to surround the use of data-link implementation. The authors suggested several areas that need more study to include:

- Risk of crew exclusion from communication loop between ATC and aircraft

- Workload modification due to manual and automatic data transfer between the data-link interface and FMS

- Transaction time variation due to manual and automatic data transfer between the data-link interface and FMS

- Risk of interference between simultaneous communications and flying actions

- Possibility of reducing errors by facilitating retention of information (e.g., messages kept on display)

- Possibility of reducing errors by using appropriate presentation modes of messages (graphic, iconic, or textual) and presentation formats of these messages (readability)

- Facilitating reaction time by adequate coding for urgent messages

- Increasing intra-cockpit communication (to ensure shared representation of flying conditions)

- Increasing visual tasks and visual channel overload

- Risk of reducing or removing party-line information

These research areas remain today as significant challenges to data-link and mixed-voice communications operations. 
Data-link may improve one source of miscommunications - the inability to get the message from one party to the other but it does not necessarily address the rest of the communications process - i.e., whether the message was understood and whether it accurately conveyed the sender's intent. These data-link issues may be more acute for NextGen - with closer spacing and more pilot responsibility for separation - especially where increased head-down time and increased workload could significantly reduce safety margins.

\subsection{Flight Deck Display Solutions}

NASA research has targeted flight-crew assessment of the modality change effects associated with data-link operations, the impact of party-line information changes, and potential mitigating factors for NextGen operations. Past research has demonstrated that the efficacy of party-line information is dependent upon crew resources, communication, and workload. These influences are undoubtedly impacted by generational versions of NextGen - in particular, the potential of ADS-B "in" capability, with traffic intent data - but the extent to which has not been quantified. NextGen net-centric concepts are reliant upon technological innovation and the avionics of current and future aircraft. As presently envisioned, data-link will provide alphanumeric information that will likely be read by the flight-crew on a display, such as a Controller Pilot Data-Link Communications (CPDLC) interface. Research suggests that data-link, that may serve to replace voice (voice-by-exception) for routine communications, may introduce a different set of safety issues due to the potential impacts of party-line information loss or inherent latencies in managing mixed voice and data pilot-ATC communications with CPDLC. Therefore, NASA has been investigating the issues of data-link and CPDLC and candidate solutions.

\section{NASA FLIGHT DECK DISPLAY CONCEPTS}

NASA has developed flight deck display concepts that focus on how data-link may be implemented for NextGen and how best to optimally display that information to the flight-crew. A primary objective of the research is to determine how to leverage advances in avionics to more intuitively present data-link messages and graphically display 4DT clearances and other traffic, and what they are intending to do (i.e., traffic intent). Research on intent is limited, particularly related to surface operations, but existing work [20] posits the substantial benefits to shared situation awareness that may accrue from such enhancements to data-link capability. (Intent is operationally defined as the information that collectively provides own-ship and other aircraft state and assigned 4DT route guidance and prediction.)

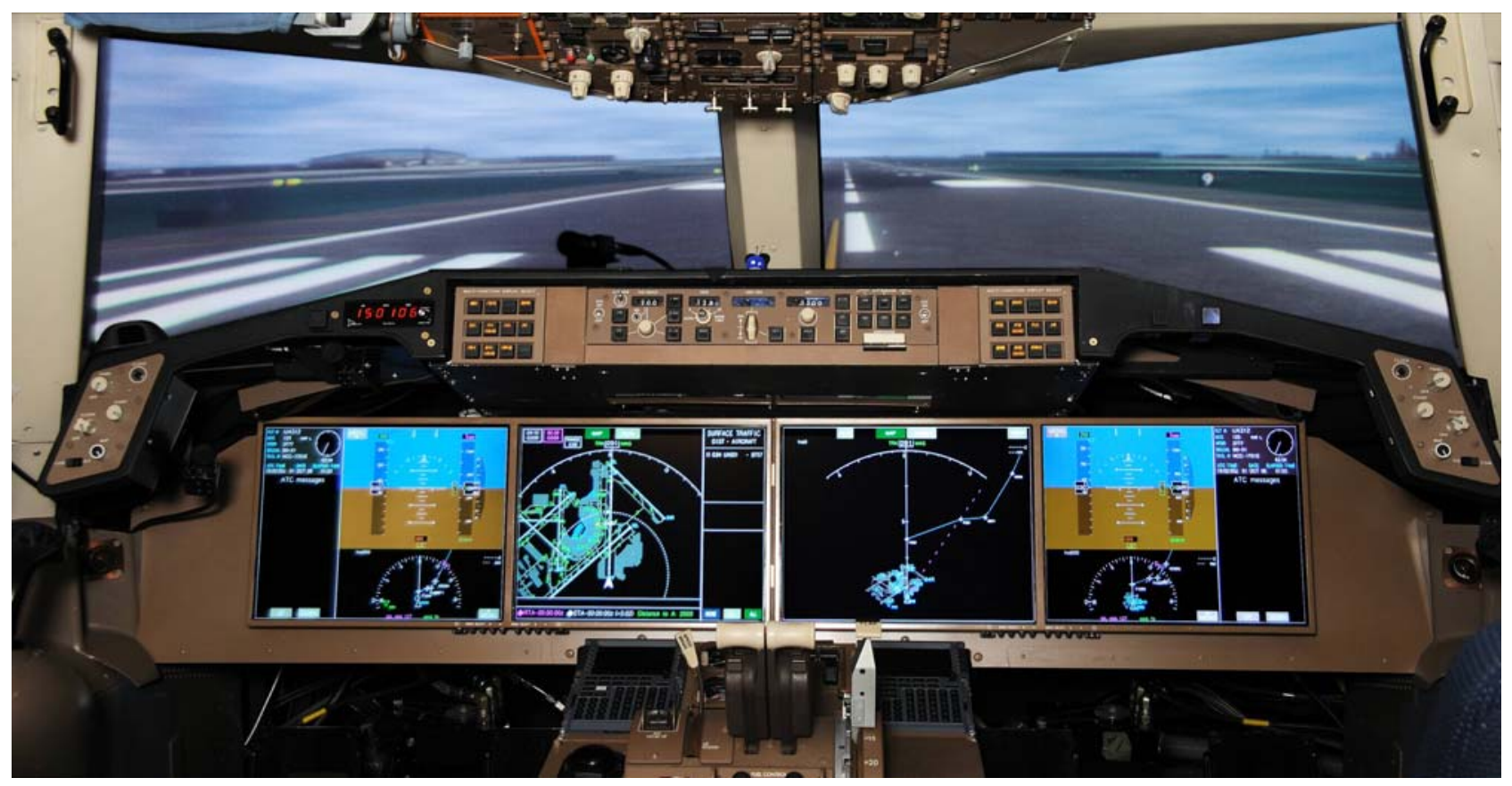

Figure 2. NASA Langley Research Flight Deck Simulation 
In the following, candidate flight deck display concepts are shown. These concepts have been designed, based on current state-of-the-art flight deck display concepts to support terminal area and surface operations. These candidate solutions are being evaluated against the issues of data-link that are postulated to be even more problematic within equivalent visual and 4DT operations envisioned for NextGen. These concepts have been implemented in NASA Langley's full-mission Research Flight Deck (RFD) simulator. The RFD instrument panel uses four 10.5” High by 13.25" Wide, 1280x1024 resolution color displays. Also, the RFD includes a Mode Control Panel (MCP), Flight Management System (FMS), Control Display Units (CDU), and hydraulic side-stick control inceptors (Figure 2).

\subsection{Primary Flight Display}

The Primary Flight Display (PFD), Navigation Display (ND), and Engine Indication and Crew Alerting System display (EICAS) were modeled after Boeing 787, Gulfstream G550 and Airbus A350 instrument panels as current state-of-theart production aircraft. The PFD (Figure 3) display unit includes an ATC message area on the outboard third of the display unit showing incoming and outgoing ATC data-link communications in alpha-numerics. Incoming messages are color-coded green while outgoing messages are white. All messages are time stamped. The captain's inboard display unit shows navigation and EICAS displays (Figure 3).
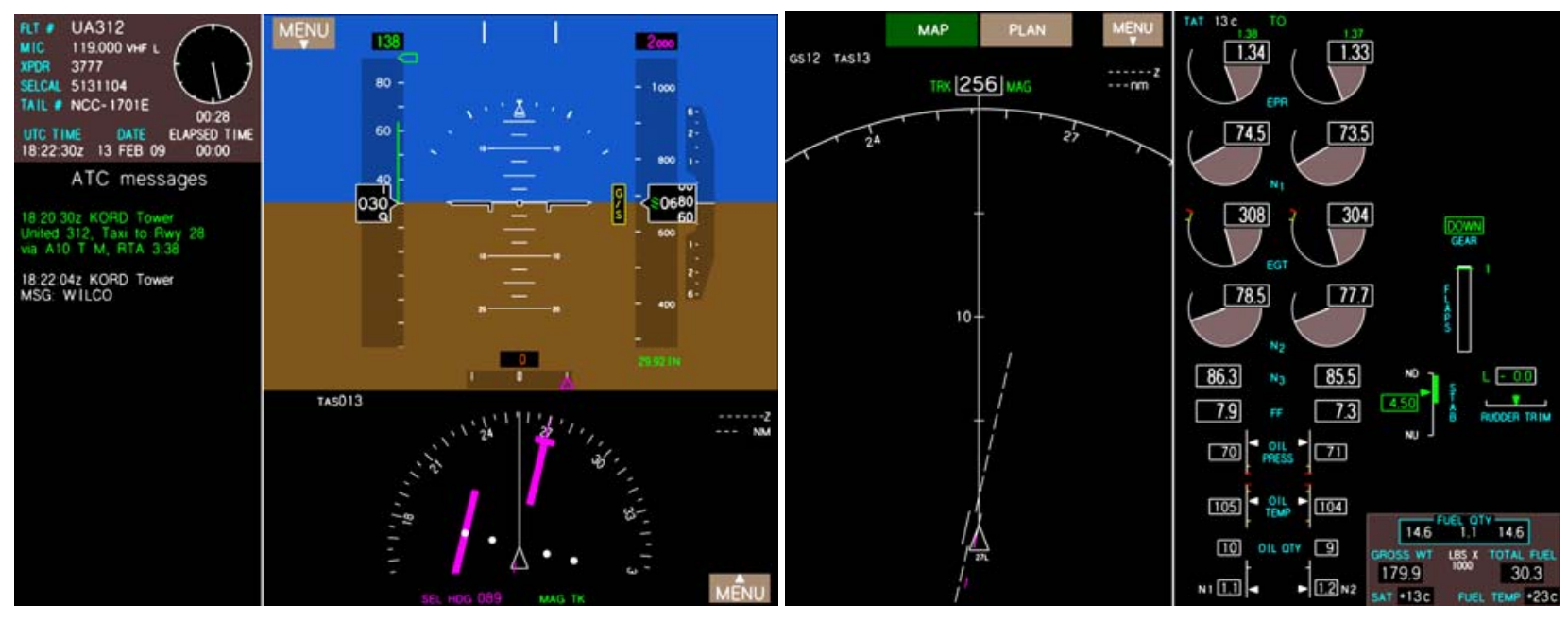

Figure 3. Primary Flight Display and Navigation Display with Half-Screen EICAS
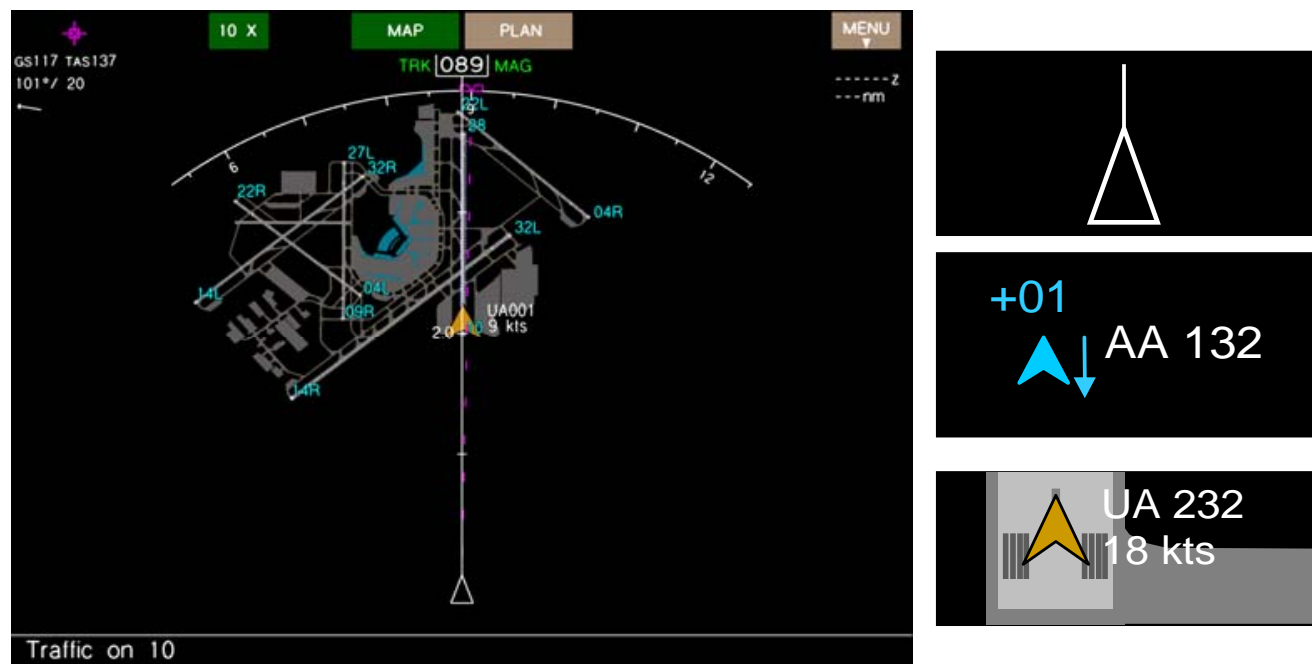

Airborne Own-ship Symbol

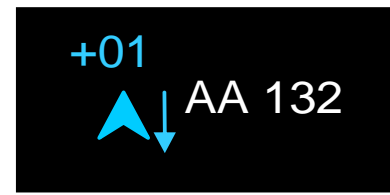

Airborne Traffic Symbol

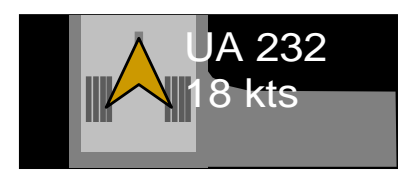

Surface Traffic Symbol

Figure 4. Navigation Display Concept Showing Airport Map 


\subsection{Navigation Display}

The first officer's inboard display (Figure 4) is a full screen moving map navigation display with high airport surface detail, including surface and airborne traffic icons. This display automatically transitions to the surface map display (described below) after landing, when the ground speed is less then 80kts (Figure 4).

\subsection{Electronic Flight Bag Display}

The Electronic Flight Bag (EFB) is used as a flight-crew's interface for ATC data-link communications (the FMS CDU may also be used), and for approach chart and airport diagram chart references. The EFB used in the RFD is a commercial off-the-shelf (COTS) Class II hardware running custom software with simulated link to the FMS CDU (Figure 5).
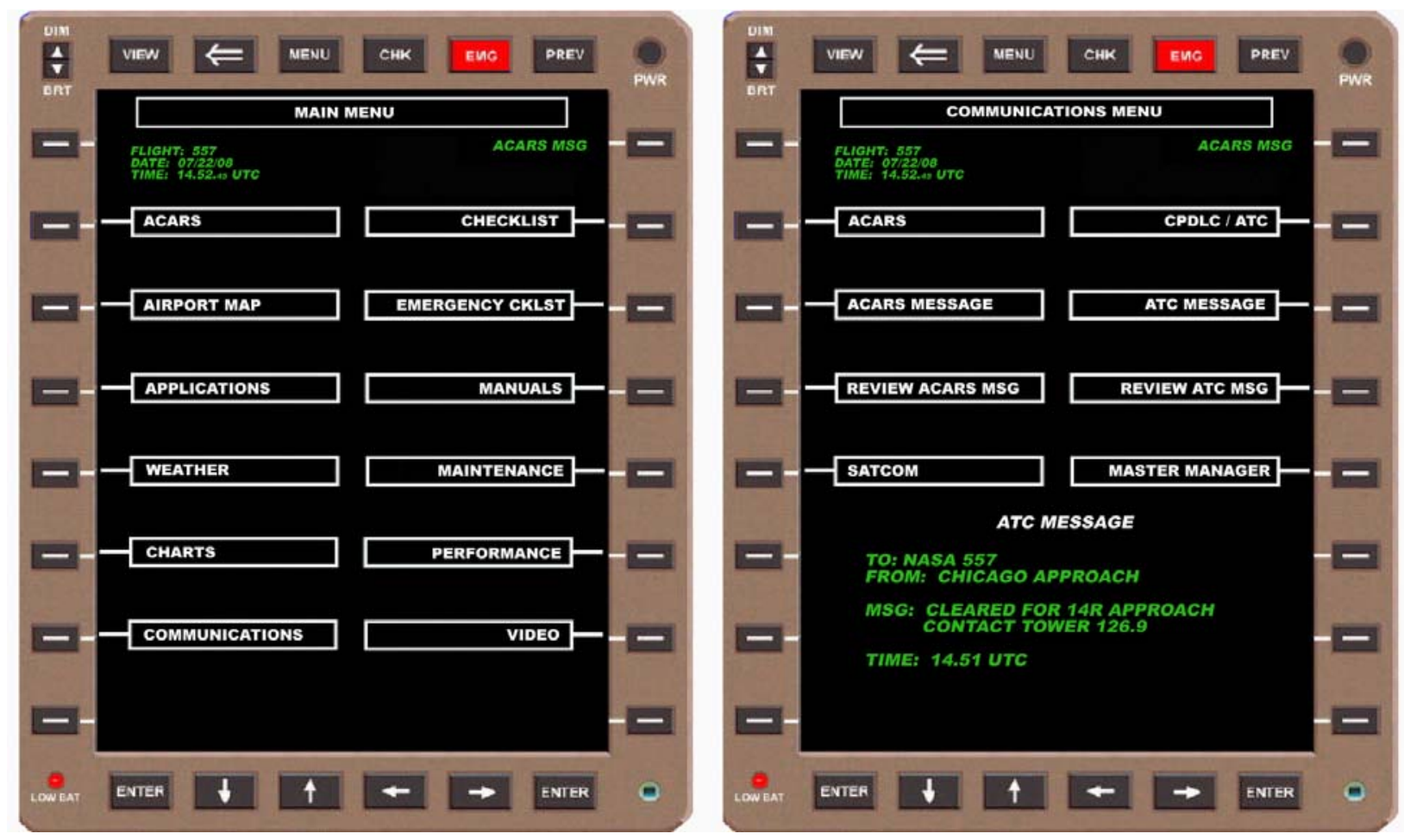

Figure 5. Examples of Electronic Flight Bag (CPDLC) Interface

\subsection{Head-Up Display}

The head-up display (HUD) concepts are evolving from Taxiway Navigation and Situation Awareness ("T-NASA") research [21] [22]. The T-NASA HUD display concepts (Figure 6) show current ground speed in digital format, the current taxiway, next cleared taxiway, centerline markers and virtual cones on the taxiway edge. Additional cues are given for turns. These cues consist of turn flags and virtual turn signs (similar to road way turn signs). Hold short lines are displayed with a single line drawn at the hold short location with a virtual stop sign. A non-conformal taxi director display provides an intuitive display of the relationship between the taxiway centerline and the aircraft's landing gear position (Jones, 2002). The T-NASA HUD system has been further enhanced using audible alerts for deviation from the assigned taxi route ("Off Route, Off Route") and unauthorized crossing of a hold line ("Crossing Hold, Crossing Hold") during data-link operating conditions [23].

HUD format modifications are being developed to accommodate new NextGen operations. 4DT utilizes dynamic algorithms to generate speed- or time-based taxi clearances to calculate the most efficient movement of all surface traffic 
and enable precise surface coordination [24] [25. Current instantiations of HUD-displayed 4DT guidance symbology use speed and time commands (upper left and right hand information in Figure 7) to the flight-crews throughout the taxi route to regulate the required timing precision of surface traffic movements. The aircraft's taxi speed may be adjusted if the pilot is unable to conform to the speed command to meet the required time-of-arrival (TOA), if traffic is unable to comply (creating a reduction in separation), or if the needs of the dynamic airport surface operation requires adjustment.

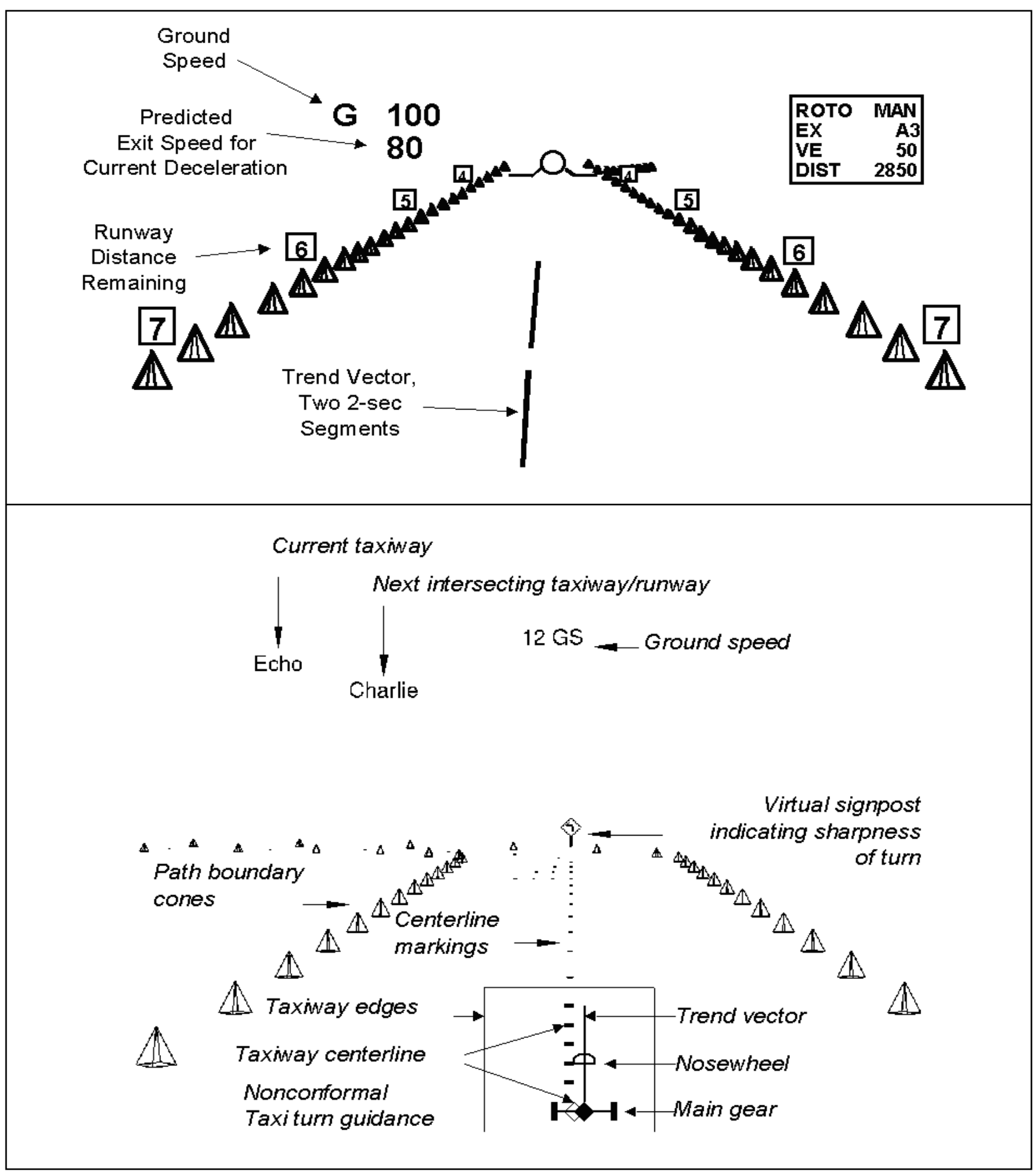

Figure 6. Head-Up Display Symbology for Surface Operations (roll-out and turn-off) 


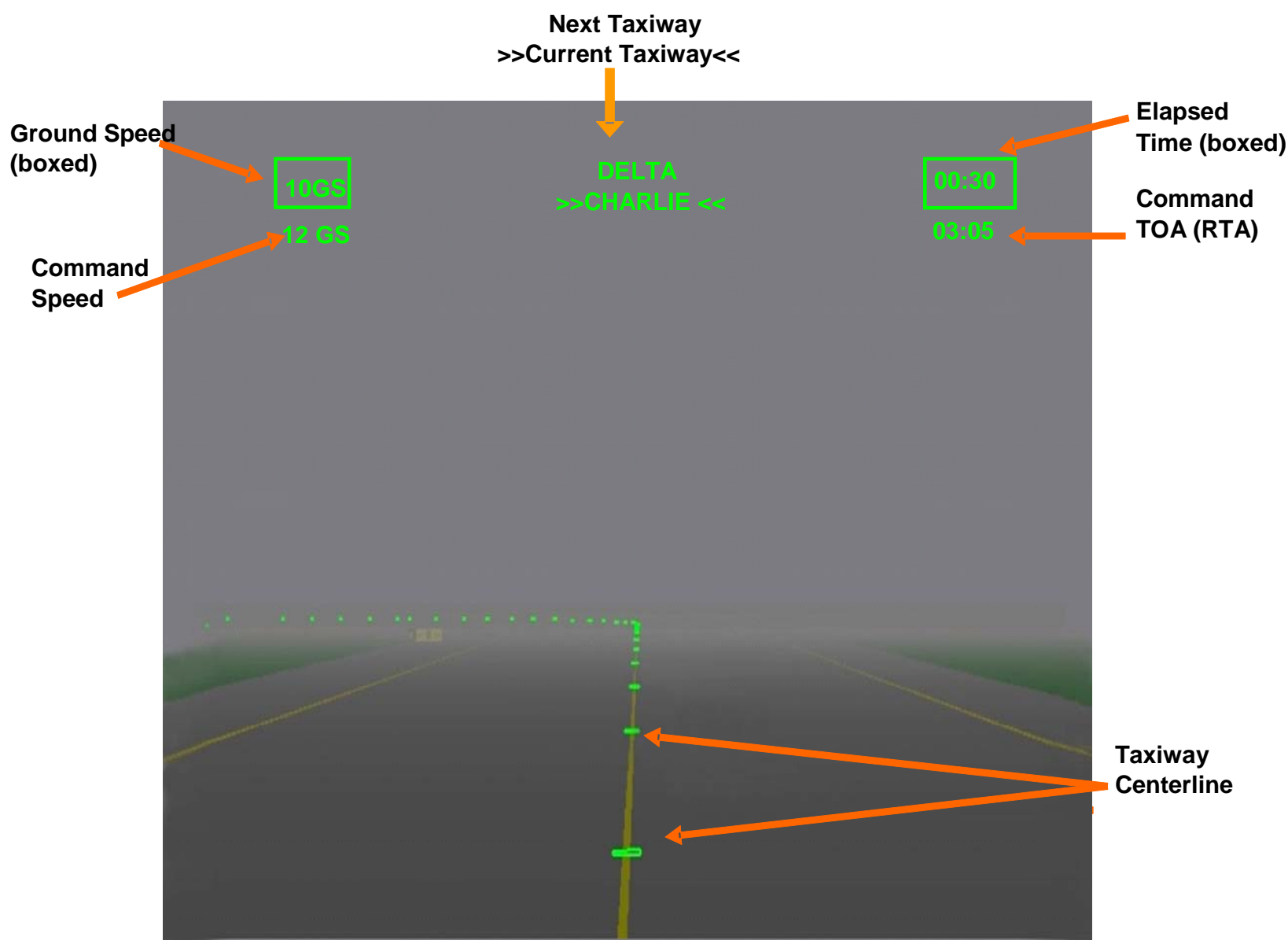

Figure 7. Head-Up Display Symbology for Surface Operations (4DT)

Surface operations research at NASA has shown that flight crews reported the greatest surface situation awareness (SA) when tactical information on a head-up display was combined with strategic information on a head-down display. Initially, crews often report that a moving map display would be a "quantum leap" in awareness over paper maps [26] . However, once presented with both head-up and head down concepts, they report higher SA compared to just a head down display. Essentially, the higher rating result is in keeping with the "eyes-out" philosophy which is ultimately how safe taxiing decisions are made (e.g., you do not want significant flight-crew head down while taxiing). Therefore, careful consideration was made in the presented concepts to encourage eyes-out while still providing the necessary information needed in a NextGen 4DT environment.

\subsection{Surface Map Display}

The advanced surface map display is presented on the pilot-not-taxiing side to minimize head-down time for the pilot performing the taxi task. The surface map display is an enhanced version of the track-up navigation display that automatically transitions from the navigation display during the landing rollout; however, it can be manually selected at any time. The surface map display design is based upon input from RTCA SC-183 working group findings in regard to element shape and color assignments, and is designed for strategic use for surface operations (to minimize head-down time). The traffic icons are medium tan colored chevrons when on the surface and cyan when airborne. Own-ship icon is a large white chevron, and the cleared taxi route is shown in magenta.

The surface map features a list of traffic on the right side of the display. The traffic list is sorted based on proximity to own-ship with the closest traffic listed first. A cursor control device can be used to select specific traffic in the list 
(magenta box indicates selected traffic) which brings up additional details of the selected traffic (lower right of Figure 8). Traffic details include: type, flight ID, speed, heading, ATC assigned route (intent), and the range / bearing from own-ship position. Traffic labels can be de-cluttered from the map graphics by selecting either "None", "All”, or "L1" (Level 1) which displays labels for the traffic selected. When selected, the traffic's chevron is highlighted with a white halo and the intended (ATC assigned) route is graphically depicted on the map in the traffic icon color (Figure 8).

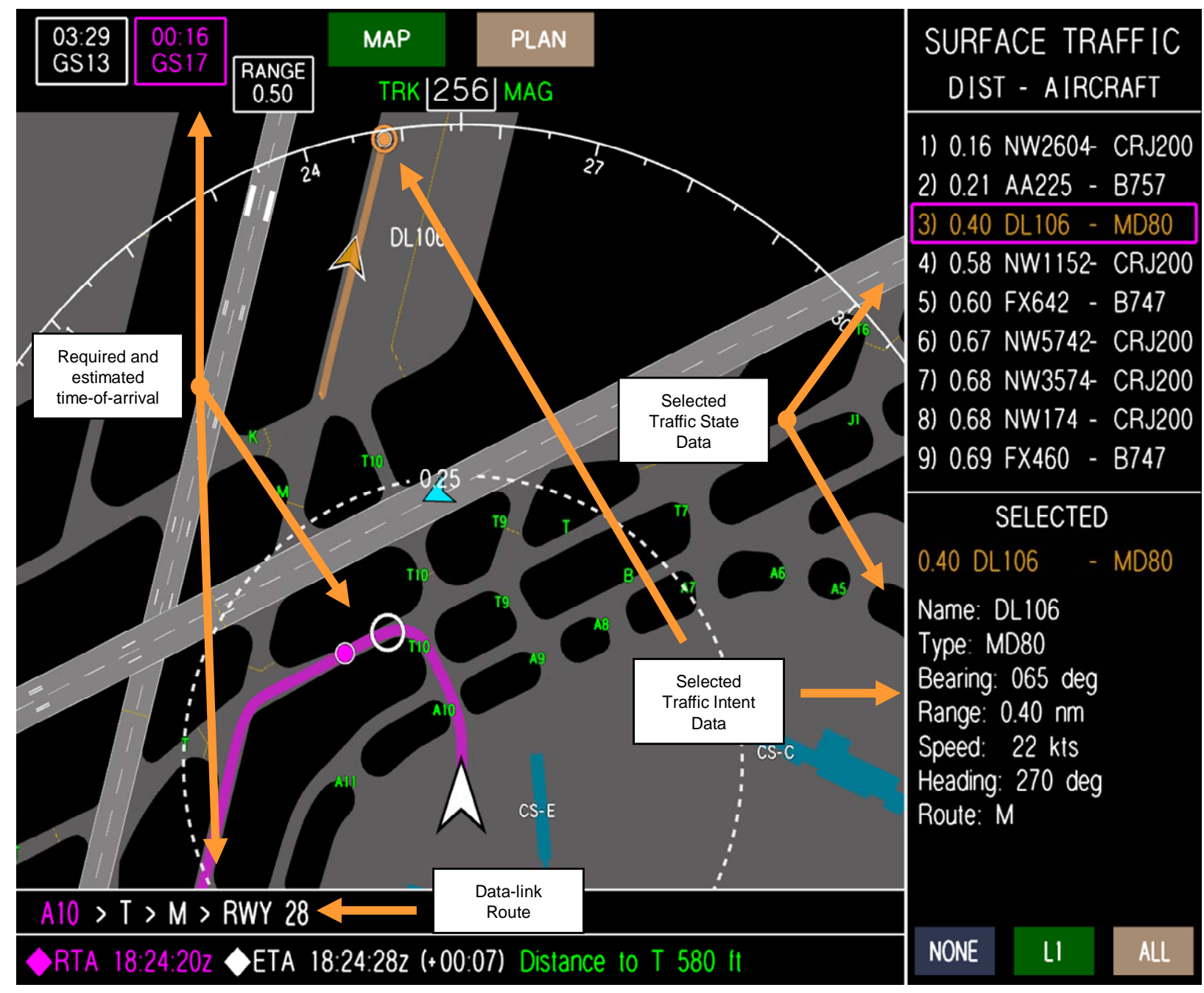

Figure 8. Surface map display concept
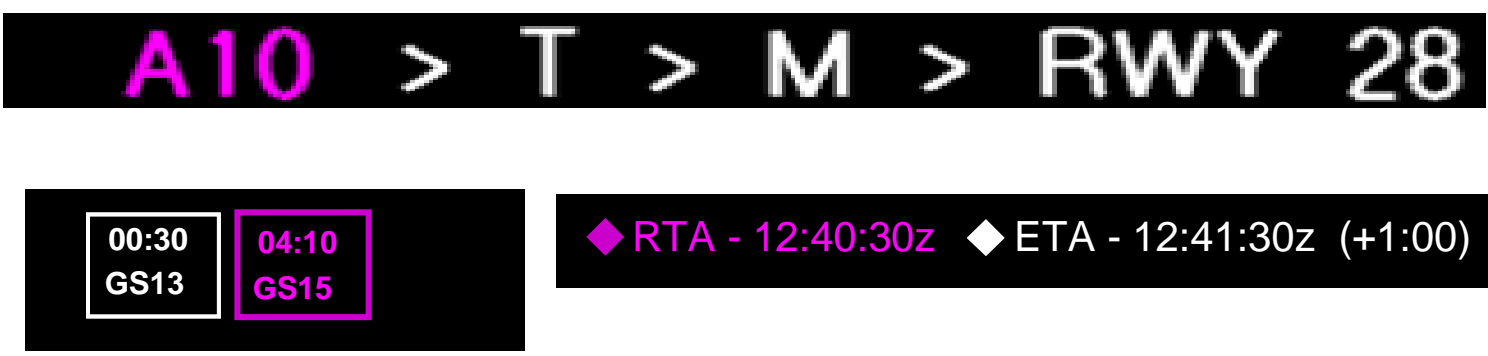

Figure 9. Required- and Estimated-Time-of-Arrival and Taxi Route Information 
The assigned taxi route is displayed on the lower center of the display as a text string, and current position along that route is highlighted in magenta. Distance to the next route segment is also displayed nearby in green text. 4D trajectory guidance information (textual) is displayed as: current state information in white fground speed, elapsed time, and Estimated Time-of-Arrival (ETA) UTC\}; while guidance information \{Required Time of Arrival (RTA) in Greenwich Mean time (UTC), Required Time Enroute (RTE) in min:sec, and guidance ground speed $\}$ is displayed in magenta (Figure 9).

Many different 4D graphical guidance symbols concepts were explored to improve on the alphanumeric speed and time guidance information. The down-selected graphical 4DT guidance concept is shown in Figure 9. The guidance cue - a magenta dot is shown on the commanded route, moving along the ATC-assigned route approximately 30 seconds ahead - and a own-ship speed symbol in white showing own-ship position estimated in 30 seconds from present speed and acceleration. The flight-crew's task is to overlay the 30 second trend symbol over the 30 sec RTA prediction symbology (Figure 10).

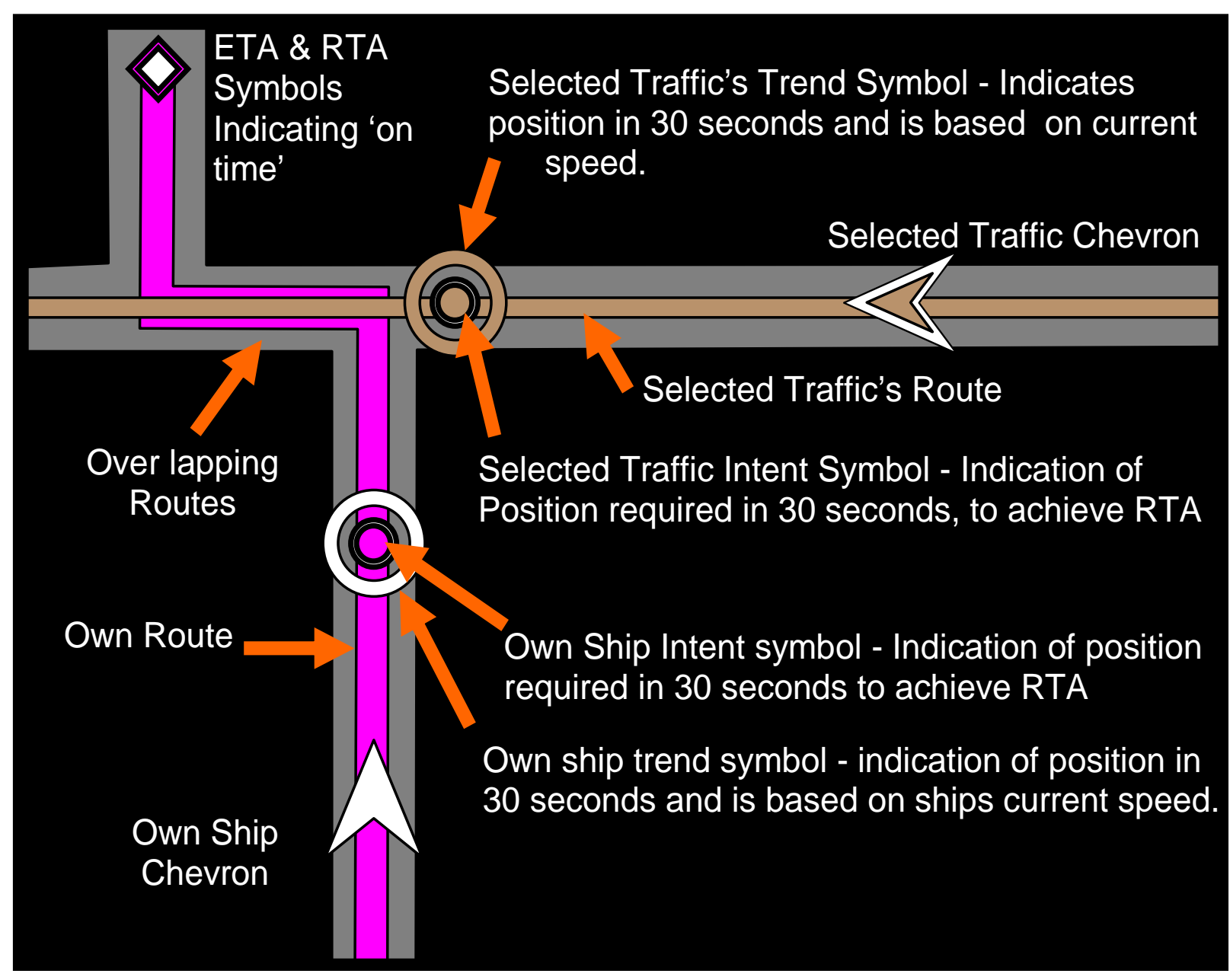

Figure 10. 4DT Graphical Surface Map Symbology

Similarly, trend and intent symbology may be displayed for the selected traffic. The symbology is designed such that conflict areas (such as crossing routes) can be quickly seen and interpreted at a glance. Further, the 30 second ahead gives strategic planning information which could aid in possible traffic conflicts. End-of-route symbology is shown as a white and magenta diamond and indicates relative ETA and RTA graphically (Figure 11). 
Indicates on time arrival - e.g. RTA - ETA is less than \pm 15 seconds

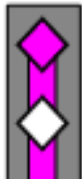

Indicates late arrival - The position of white diamond along route indicates estimated location at the RTA time

8

Indicates early arrival greater than 15 seconds early

Figure 11. Trend and Intent 4DT Surface Map Symbology

\subsection{Conflict Detection and Alerting}

Runway incursions are a serious aviation safety hazard. The National Transportation Safety Board continues to have improving runway safety on its most wanted list of transportation safety improvements for aviation (National Transportation Safety Board 2008]. In the four year period between 2004 and 2007, 1,353 runway incursion events were reported, which is a rate of almost 1 runway incursion event per day (Federal Aviation Administration 2008]. These statistics and events are cause enough for alarm, but without proactive counter-measures, the increase in air traffic forecasted under NextGen could potentially result in catastrophic increases in runway incursion accidents. Numerous efforts have been launched by the FAA, industry, and others to reduce the frequency of runway incursions and the risk of runway collisions to meet the recommendations put forth by the NTSB (National Transportation Safety Board 2000]. Current FAA initiatives include a combination of technology, infrastructure, procedural, and training interventions (Federal Aviation Administration 2008]. Although the FAA is supporting the development of airport moving map displays and electronic flight bag display devices, currently there is not a system available (either ground or aircraftbased) that directly provides pilots with alerts of potential runway conflicts with other traffic.

In today's operations, the principal airborne method of CD\&R for separation assurance is provided by the Traffic Alert and Collision Avoidance System (TCAS). TCAS predicts a penetration to an aircraft's airspace and provides associated alerts to the flight crew. TCAS has been developed and improved for over 15 years and has been very effective in reducing or eliminating airborne collisions. This system has limitations in the vicinity of airports and TCAS alerts are inhibited at low altitudes. Resolution Advisories (RAs) are not issued below 1000 feet Above Ground Level (AGL) and audible Traffic Advisories (TAs) are not issued below 500 feet AGL (Federal Aviation Administration 2000]. Research to date indicates that the use of TCAS may work for envisioned trajectory-based 4-D operations (Ivanescu, et. al., 2004], but the suitability of TCAS degrades in operations nearing the airport (Pritchett, et. al., 1995]. A newly formed RTCA committee (SC-218, Future ADS-B/TCAS Relationships) is assessing the relationship between ADS-B and TCAS from 2020 to 2025 and is expected to further develop concepts for interoperation between ADS-B and TCAS (RTCA 2008].

The NextGen concept proposes the use of ground-based automation to schedule surface traffic and generate 4-D taxi clearances to enable precise departure times and limited simultaneous runway occupancy (Joint Planning \& Development Office 2007]. This move toward 4-D surface operations pushes the CD\&R need beyond the runway and must include all surface operations. Research has been initiated to determine the information display requirements for presentation of automated 4-D taxi clearances to the pilot and the ability of the pilot to comply with the 4-D clearances (Williams, et. al., 2006]. Research is yet to be conducted to determine the safety impacts of following 4-D taxi clearances. It is anticipated that the pilot may be so focused on following 4-D clearances to meet scheduled arrival times that unintentional taxi conflicts result. If this is the case, taxi conflict detection capability becomes critical.

The flight deck display concepts, described above, provide needed situation awareness to enable EVO and 4DT terminal area and surface operations. To further enhance the safety of these technologies, NASA has developed a conflict detection and resolution (CD\&R) system to provide additional protective layer of prevention in the event that the tactical or strategic awareness of the flight crew is insufficient and presents a potentially hazardous situation. The system 
integrates airborne and ground-based technologies which include flight deck displays, conflict detection and alerting algorithms, on-board position determination systems, airport surveillance systems, and controller-pilot data link communications.
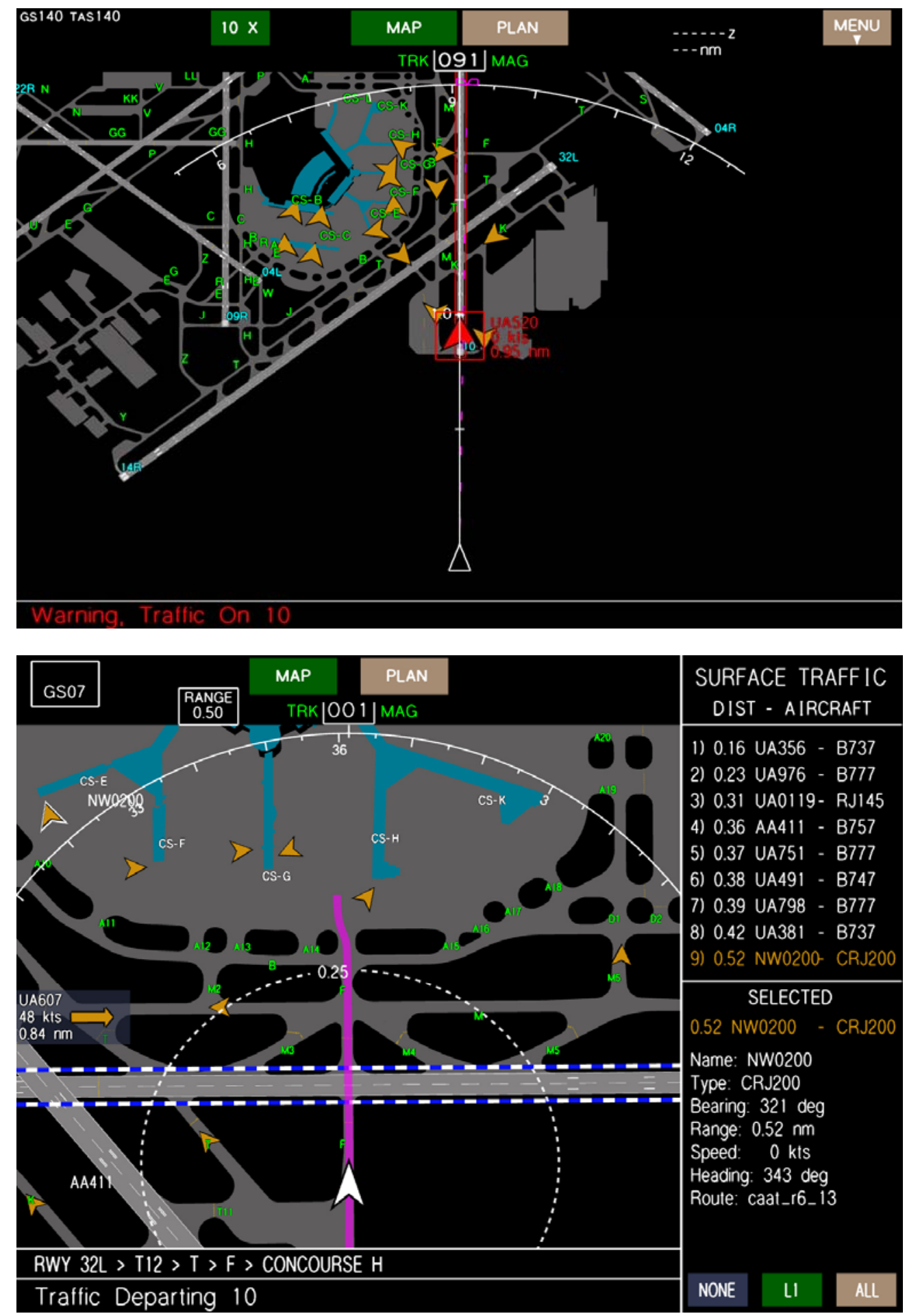

Figure 12. Runway incursion warning alert (left) and active runway occupied primary indication (right) 

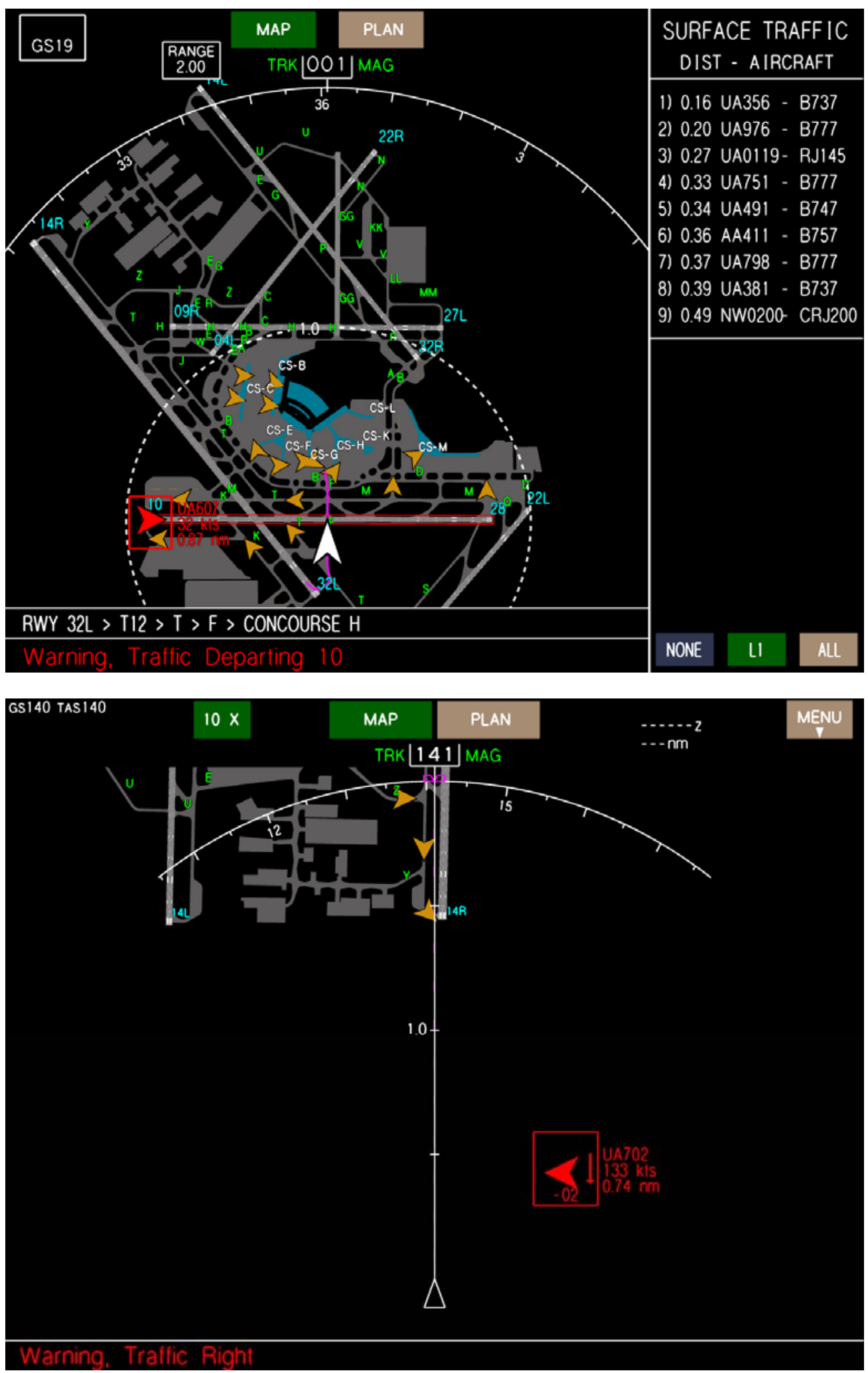

Figure 13. Surface taxi conflict alert (left) and low-altitude traffic warning (right) 
The CD\&R concept (termed, “Collision Avoidance for Airport Traffic” or CAAT) continually monitors own-ship and traffic data to detect conflicts on the runway, at low altitudes near the airport, and during taxi and ramp operations for multiple classes of aircraft and surface vehicles. Alerts designed for flight crew awareness may identify potentially hazardous operational conditions that could require immediate flight crew response (see Figures 12 and 13). This work builds from substantial NASA research and testing for surface operations situation awareness and runway incursion conflict detection and alerting (i.e., the Runway Incursion Prevention System (RIPS)) [36] - 39]. NASA is also investigating the concept of providing enhanced situation relevant information for potential runway safety hazards. These indications are intended to increase the flight crews' traffic SA that could affect runway safety (Figures 12-13). Research is also being initiated regarding the feasibility of providing resolution advisories for conflicts in the TMA to effectively resolve conflict situations without producing undesired consequences.

\section{CURRENT NASA RESEARCH}

To achieve the NextGen vision, research is necessary to proactively investigate and overcome potential technology and safety barriers in the areas of surface traffic optimization, maximum runway capacity through reduced runway occupancy time, simultaneous single runway operations, 4DT design and operation, and equivalent visual operations, among others [35, 41].

\subsection{NextGen Data-Link Communications}

Research at NASA Langley Research Center is currently focused on how data-link implementations (i.e., redundant, supplementary, or replacement to voice) and mixed-modality communication (i.e., voice and data-link) impacts crew decision-making, workload, situation awareness, and crew coordination during off-nominal operational situations conducted under envisioned 4DT EVO NextGen operational concepts. NextGen communication technology will be implemented in evolutionary stages. Therefore, NASA is currently conducting an experimental study (data collection on-going at time of publication but planned for completion in April 2009) that is evaluating four communication modes: (a) voice with redundant data-link (data-link as redundant to voice), (b) voice and data-link (data-link as supplement to voice), (c) data-link only (data-link as replacement for voice), and (d) data-link only with intent.

The methodology was designed to emulate envisioned NextGen surface operations to include 4DT (required-time-ofarrivals) and equivalent visual operations clearances and procedures, high tempo traffic density and patterns, and datalinked landing and taxi clearances prior to the final approach fix (see JPDO, August 2007). Flight crews were paired by airline and current job duties (i.e., Captain or First-Officer) and were asked to fly 24 trials with varying tasks (approach, landing, or departure) and four communication modes. The voice + data-link as redundant to voice condition required the pilot-not-flying to respond via voice and data-link (through EFB) to ATC clearances while all clearances and pilot read-backs were heard on the party-line. The voice + data-link as supplement to voice condition provided only pilot read-backs on the VHF channel and the flight crew was asked to respond via voice and data-link. The data-link only condition (i.e., data-link as replacement for voice or voice-by-exception) had no ATC clearances or pilot read-backs over the voice channel and the participants were required to respond only through data-link (except for exigent situations). Finally, the data-link only + traffic intent condition was identical to the data-link only condition; however, the surface map display presented additional traffic intent information (e.g., selected traffic route and destination information).

Off-nominal scenarios tested included incorrect clearances, runway incursions, and data-link issues. The objectives of the scenarios were to evaluate whether the flight-crews would recognize off-nominal situations (which might become hazardous) and how they would respond to these events. The incorrect clearance scenario, for example, data-linked a clearance, that resulted in a route disconnect (ROUTE DISCO) for the taxi path, but was stated correctly by the controller over the voice channel. Therefore, the flight crew could detect the anomaly if they heard the dissociation between the voice and data-link clearances (if voice was part of the display condition for that crew) or by reviewing the data-link clearance fully prior to WILCO (or later during taxiing). In this case, voice (as redundant to data-link) was hypothesized to result in greater awareness of the error. Other off-nominal scenarios tested the party-line effect in which awareness of hear-backs and read-backs (chatter) might enhance SA. For example, one off-nominal scenario included a potential runway incursion in which an aircraft erroneously taxied onto the runway, was cleared for take-off on the active runway, and created a conflict with the subjects who were on final approach to the same runway. The blunder aircraft had responded to ATC, but did not correctly acknowledge the clearance, and the controller failed to recognize 
the error (expectancy heuristic). The aircraft consequently remained on the runway, unaware that they were supposed to depart because of the aircraft on approach behind them. In this case, it was hypothesized that having party-line information would clue the flight-crew that an aircraft was landing on the occupied runway. Also, having data-link with traffic intent might alert the flight-crew to the runway hazard. Data collected to date has confirmed these hypotheses, although this remains premature for conclusions.

\subsection{NextGen Traffic Intent Surface Map Displays}
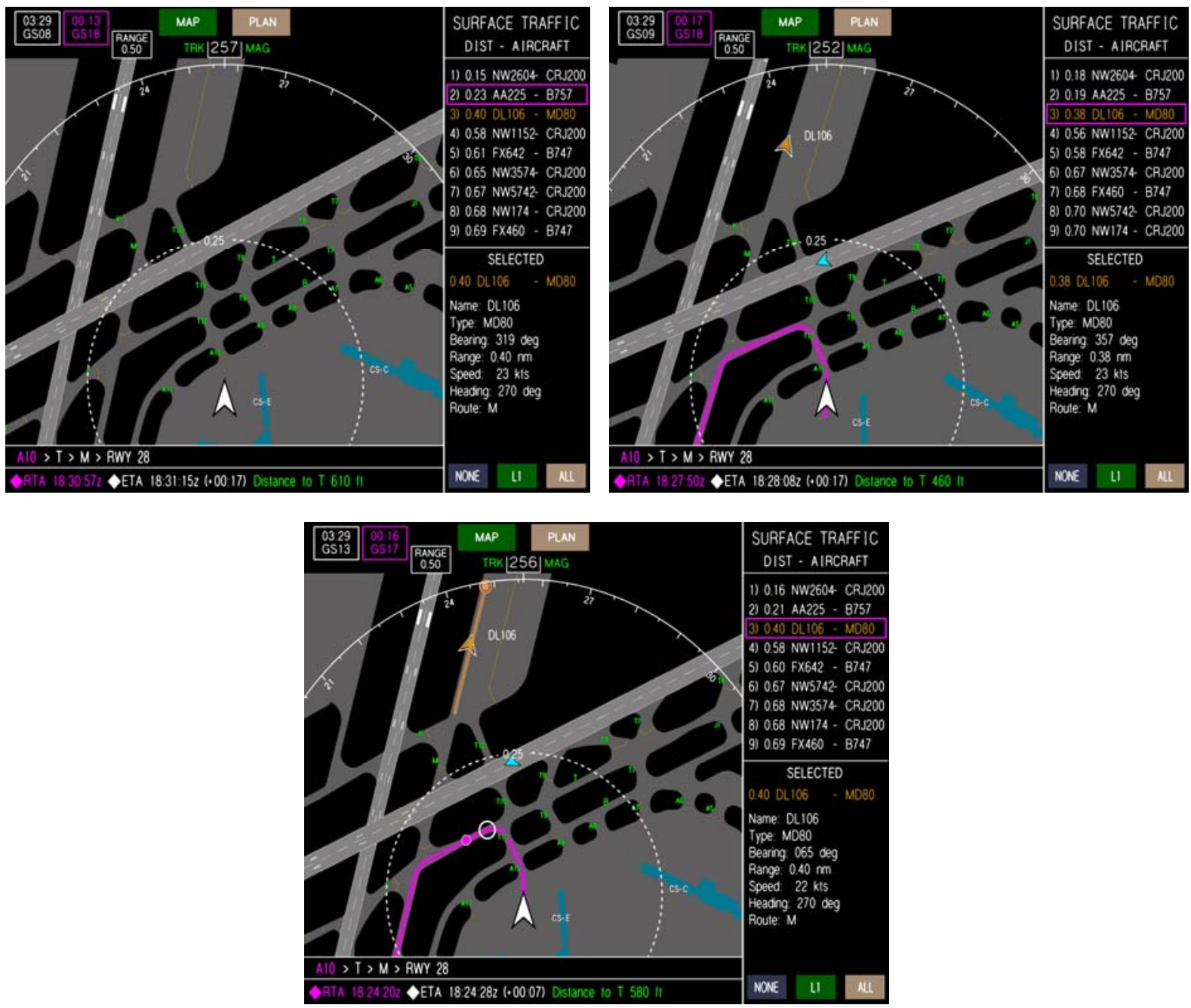

Figure 14. Experimental surface map traffic intent display concepts tested (concepts a, b, and c, respectively)

Another experiment, currently on-going, is evaluating how traffic intent information may best be displayed on a surface map display. Intent is operationally defined as the information that collectively provides own-ship and other aircraft state and assigned 4DT route guidance and prediction (e.g., ADS-B in/out surface message; CPDLC-all; TIS-B; etc). The objectives of the research are to determine what critical elements are needed to enable EVO and 4DT surface operations efficiently but above all safely. Essentially, the questions being asked are: 1) whether it is sufficient to just present the traffic intent information textually (e.g., data-link clearances of other aircraft); or, 2) is it required to have a graphical interface of traffic intent display. For this experiment, the display conditions are: (a) a baseline NextGen aircraft capability to include a surface map display with own-ship only and CPDLC capability with textual traffic state information; (b) an intermediate NextGen concept to include a surface map display with traffic and manual query capability of other aircraft intent and graphical depiction of own-ship, target aircraft, and 4DT paths; and (c) an 
advanced NextGen concept that automatically prioritizes and selects aircraft while depicting graphical own-ship and traffic 4DT guidance and conformance (Figure 14).

As described above, the scenarios and tasks represent those being conceptualized, and are representative of future NextGen surface operations [41]. Flight crews are paired by airline and current job duties (i.e., Captain or First-Officer) and are asked to fly 22 trials with varying tasks (approach, landing, or departure) and three surface map display conditions (described above). Off-nominal events are, again, included to test for surface conflicts and taxi blunders, incorrect data-link clearances, detection of non-participating objects, and runway incursions. The hypothesis for these trials was that the advanced display concept, because of the graphical 4DT guidance and conformance information, would significantly enhance flight-crew detection of incorrect data-link clearances, runway incursions and taxi blunder situations. Furthermore, off-nominal situations tested were designed to determine whether the flight-crew would become attention-captured by the potential compellingness of the display concepts and possibly increased head-down time while decreasing outside scanning for traffic and other hazards. Results purport to confirm these hypotheses, without evidence for increased heads-down time or failure to detect hazards (not present in the surface map display), although any conclusion remains premature at this stage of data collection.

\subsection{NextGen Conflict Detection and Alerting}

A third study is also currently being conducted to evaluate the concepts and criteria for indications and alerts of potential airport traffic conflicts during low altitude TMA operations, taxi, and runway incursion scenarios; indication and alerting display concepts; and conflict resolution advisory concepts. The concepts were generated to complement an RTCA SC186 Working Group that is developing an application description for aircraft-based conflict detection and alerting. The study methodology was designed to obtain specific feedback on the usefulness of indications for providing enhanced situation relevant information for potential runway safety hazards. Also, two different alerting methods for runway incursion conflict detection from a NASA-developed conflict detection algorithm and example criteria under development are being evaluated. Conflict detection is also being evaluated for taxi and low-altitude operation. Feedback is being obtained on the preferred indication and alerting phraseology and for possible resolutions for particular operations.

\section{FUTURE RESEARCH}

NASA research is on-going to investigate the effects of data-link communications for NextGen 4DT and EVO surface operations and to determine whether the graphical display of traffic intent would mitigate, or eliminate, anticipated effects of voice-by-exception flight-deck communications. Future research will also focus on developing CD\&R and surface display concepts to meet the challenges of NextGen operations.

\section{ACKNOWLEDGMENTS}

Research described in the paper is supported under NASA's Airspace Systems Program, Air Portal Project (Safe and Efficient Surface Operations) and the Aviation Safety Program, Integrated Intelligent Flight Deck Project. The authors would like to acknowledgment the tremendous contributions of many technicians, programmers, and engineers who support / have supported the research. Notable among them are Dr. Robert M. Norman, Lynda Kramer, Steven Williams, Steve Young, Sharon Otero, Glover Barker, Jerry Karwac, and Wei Anderson.

\section{REFERENCES}

[1] Prinzo, O.V. (1996). An Analysis of Approach Control/Pilot Voice Communications. FAA Civil Aeromedical Institute, (DOT/FAA/AM-96/26), p. 3-44.

[2] Cardosi, K.M. (1993): An Analysis Of En Route Controller-Pilot Communications. Report No. DOT/FAA/RD - 93/11. Washington, DC: Department of Transportation, Federal Aviation Administration.

[3] Morrow, D and Rodvold, M. (1993) The Influence of ATC Message Length and Timing on Pilot Communication. NASA Contractor Report 177621. August 1993

[4] Cushing, S. (1994). Fatal Words. Chicago, IL: University of Chicago Press.

[5] Eurocontrol (2005): Initial Communications Operating Concepts And Requirements For The Future Radio System. Eurocontrol/FAA Future Communications Study Operational Concepts and Requirements, January 2005.

[6] Kerns, K. (1991): Data-Link Communication Between Controllers and Pilots: A Review and Synthesis of the Simulation Literature. International Journal of Aviation Psychology 1991, Vol. 1, No. 3, Pages 181-204. 
[7] Federal Aviation Administration (1995): User Benefits of Two-Way Data Link ATC Communications: Aircraft Delay and Flight Efficiency in Congested En Route Airspace. Federal Aviation Administration Data Link Benefits Study Team FAA Report FAA/CT-95-4, February 1995.

[8] Federal Aviation Administration (1996a): The Interfaces Between Flightcrews and Modern Flight Deck Systems. Federal Aviation Administration Human Factors Team Report. June 1996.

[9] Federal Aviation Administration (1996b). Benefits of Controller-Pilot Data Link ATC Communications in Terminal Airspace. Federal Aviation Administration Data Link Benefits Study Team. FAA Report FAA/CT-96-3, September 1996.

[10] Lozito, S. A., McGann, S. A. and Corker, K. (1993): Data link air traffic control and flight deck environments: Experiments in flight crew performance. In R. E. Jensen and D. Neumeister (Eds.), Proceedings of the 7th International Symposium on Aviation Psychology. Columbus, OH: The Ohio State University, 1993, pp. 1009-1015.

[11] Corwin, W.H. and McCauley, H. (1990): Considerations for the retrofit of data link. SAE, Aerospace Technology Conference and Exposition, Long Beach, CA; United States; 1-4 Oct. 1990.

[12] Andre, A.D., Lins, J.M.C., and Wilson, J. (2003): Conveying Message Criticality Via Datalink. Proceedings of the Twelfth International Symposium on Aviation Psychology, pp. 54-59. Dayton, OH: Wright State University.

[13] Talotta, N. J., and Shingledecker, C. (1992): Controller Evaluation Of Initial Data Link Terminal Air Traffic Control Services: Mini-Study 3, Report No. DOT/FAA/CT-92/18, Volume I. Washington, DC: U.S. Department of Transportation, Federal Aviation Administration. 1992.

[14] Groce, J. L. and Boucek, G. P. (1987): Air transport crew tasking in an ATC data link environment. SAE Tech. Paper 871764. Warrendale, PA: SAE International. 1987

[15] van Gent, R.N.H.W. (1995): Human Factors Issues With Airborne Data Link; Towards Increased Crew Acceptance For Both En-Route And Terminal Flight Operations. National Aerospace Laboratory NLR TP 95666, Amsterdam, NL, 1995.

[16] Waller, M. C., \& Lohr, G. W. (1989): A Piloted Simulation Of Data Link ATC Message Exchange. NASATech. Paper 2859. Hampton, VA: NASA Langley Research Center. 1989.

[17] Knox, C. E. and Scalon, C. H. (1991): Flight Tests With A Data Link Used For Air Traffic Control Information Exchange. NASA Tech. Paper 3135. Hampton, VA: NASA Langley Research Center, 1991

[18] Midkiff, A. H., and Hansman, R. J., Jr. (1993): Identification Of Important "Party Line" Information Elements And Implications For Situational Awareness In The Datalink Environment. Air Traffic Control Quarterly, 1(1), 5-30.

[19] Navarro, C. and Sikorski, S. (1999): Datalink Communication in Flight Deck Operations: A Synthesis of Recent Studies. International Journal of Aviation Psychology 1999, Vol. 9, No. 4, Pages 361-376.

[20] Williams, J., Hooey, B.L., \& Foyle, D.C. (2007). Pilot conformance to time-based taxi clearances: Implications for advanced surface traffic management systems. Human Centered System Lab Technical Report (HCSL-07-02). December, 2007.

[21] D. C. Foyle, A. D. Andre, R. S. McCann, E. Wenzel, D. Begault, and V. Battiste. Taxiway navigation and situation awareness (TNASA) system: Problem, design philosophy and description of an integrated display suite for low-visibility airport surface operations. SAE Transactions: Journal of Aerospace, 105:1411\{1418, 1996.

[22] R. S. McCann, B. L. Hooey, B. Parke, D. C. Foyle, A. D. Andre, \& B. Kanki. An evaluation of the taxiway navigation and situation awareness (T-NASA) system in high-fidelity simulation. SAE Transactions: Journal of Aerospace, 107:1612\{1625, 1998.

[23] Jones, D. R., Quach, C. C., and Young, S. D. (2001): Runway Incursion Prevention System - Demonstration and Testing at the Dallas/Fort Worth International Airport, Proceedings of the $20^{\text {th }}$ Digital Avionics Systems Conference, 2001.

[24] Cheng, V.H. L., Yeh, A., Diaz, G.M., \& Foyle, D.C. (2004). Surface-operation benefits of a collaborative automation concept. Proceedings of the AIAA Guidance, Navigation, and Control Conference, Paper AIAA 2004-5409.

[25 Rathinam, S., Montoya, J., and Jung, Y. (2008). An optimization model for reducing aircraft taxi times at the Dallas Fort Worth International Airport. 26th International Congress of the Aeronautical Sciences (ICAS) Anchorage, Alaska, Sep. 14-19, 2008.

[26] Arthur, J.J., Prinzel, L.J., Bailey, R.E., Shelton, K.J., Williams, S.P., Kramer, L.J., Norman, R.M. (2008). Head-Worn Display Concepts for Surface Operations for Commercial Aircraft. NASA TP-2008-215321+

[27] National Transportation Safety Board (2008): NTSB Most Wanted List Transportation Safety Improvements, www.ntsb.gov/recs/mostwanted/index.htm, November 2008.

[28] Federal Aviation Administration (2008) FAA Runway Safety Report. Federal Aviation Administration Office of Runway Safety, June 2008.

[29] National Transportation Safety Board (2000) Safety Recommendation, Letter to the FAA Administrator, A-00-66, July 2000.

[30] Federal Aviation Administration (2000): Introduction to TCAS II, Version 7.

[31] Ivanescu, D., Powell, D., Shaw, C., Hoffman, E., and Zeghal, K., (2004): Effect of Aircraft Self-Merging in Sequence on an Airborne Collision Avoidance System, AIAA Guidance, Navigation, and Control Conference and Exhibit, AIAA $2004-4994$.

[32] Pritchett, A.R. and Hansman, R.J. (1995): Variations In "Party Line" Information Importance Between Pilots Of Different Characteristics. Presented At The Eighth International Symposium On Aviation Psychology Columbus, Oh, April, 1995.

[33] RTCA (2008): Two New Committees Approved at PMC: Terrain and Airport Databases and Future ADS-B/TCAS Relationships, RTCA Digest, No. 182.

[34] Foyle, D.C., Williams, J.L., \& Hooey, B.L. (2008). Toward the development of information requirements of time-based (4-D) taxi clearances: Pilot-in-the-loop results. NASA Airspace Systems Program Technical Interchange Meeting, Austin, TX March 17-20, 2008. 
[35] Joint Planning \& Development Office (2007): Concept of Operations for the Next Generation Air Transportation System, Version 2.0, June 2007.

[36] Green, D. F. (2006): Runway Safety Monitor Algorithm for Single and Crossing Runway Incursion Detection and Alerting, NASA/CR-2006-214275.

[37] Jones, D. R. (2002): Runway Incursion Prevention System Simulation Evaluation. Proceedings of the $21^{\text {st }}$ Digital Avionics Systems Conference, Irvine, CA, Oct. 27 - 31, 2002

[38] Jones, D. R. (2005): Runway Incursion Prevention System Testing at the Wallops Flight Facility, Proceedings of the SPIE Defense \& Security Symposium, 2005.

[39] D. R. Jones and J. M. Rankin. A system for preventing runway incursions. Journal of Air Traffic Control, 44(3), July \{ September 2002

[40] Jones, D. R., and Prinzel, L. J., III (2006): Runway Incursion Prevention for General Aviation Operations, Proceedings of the 25 ${ }^{\text {th }}$ Digital Avionics Systems Conference, 2006.

[41] Joint Planning \& Development Office (2007): Concept of Operations for the Next Generation Air Transportation System, Version 2.0, August, 2007) 